\title{
Development of Analytical Method for Predicting Residual Mechanical Properties of Corroded Steel Plates
}

\author{
J. M. R. S. Appuhamy, ${ }^{1}$ M. Ohga, ${ }^{1}$ T. Kaita, ${ }^{2}$ K. Fujii, ${ }^{3}$ and P. B. R. Dissanayake ${ }^{4}$ \\ ${ }^{1}$ Department of Civil and Environmental Engineering, Ehime University, Matsuyama 790-8577, Japan \\ ${ }^{2}$ Department of Civil Engineering and Architecture, Tokuyama College of Technology, Shunan 745-8585, Japan \\ ${ }^{3}$ Department of Civil and Environmental Engineering, Hiroshima University, Higashi-Hiroshima 739-8511, Japan \\ ${ }^{4}$ Department of Civil Engineering, University of Peradeniya, Peradeniya 20400, Sri Lanka \\ Correspondence should be addressed to J. M. R. S. Appuhamy, jmruwan@yahoo.com
}

Received 22 September 2010; Revised 21 January 2011; Accepted 25 March 2011

Academic Editor: Chang-Jian Lin

Copyright (๑) 2011 J. M. R. S. Appuhamy et al. This is an open access article distributed under the Creative Commons Attribution License, which permits unrestricted use, distribution, and reproduction in any medium, provided the original work is properly cited.

Bridge infrastructure maintenance and assurance of adequate safety is of paramount importance in transportation engineering and maintenance management industry. Corrosion causes strength deterioration, leading to impairment of its operation and progressive weakening of the structure. Since the actual corroded surfaces are different from each other, only experimental approach is not enough to estimate the remaining strength of corroded members. However, in modern practices, numerical simulation is being used to replace the time-consuming and expensive experimental work and to comprehend on the lack of knowledge on mechanical behavior, stress distribution, ultimate behavior, and so on. This paper presents the nonlinear FEM analyses results of many corroded steel plates and compares them with their respective tensile coupon tests. Further, the feasibility of establishing an accurate analytical methodology to predict the residual strength capacities of a corroded steel member with lesser number of measuring points is also discussed.

\section{Introduction}

Major steel bridges are usually the crucial elements of the road and railway infrastructures. Very often they constitute a part of critical links between highly habited areas. As a consequence, their closure or traffic capacity reduction causes major inconveniences for the users and results in significant losses to the economy. With aging, corrosion becomes one of the major causes of deterioration of steel bridges, and their damages seriously affect their durability. It is very difficult to retrofit or rebuild those aged bridges at the same time. Therefore, it is important to evaluate the remaining strength capacities of those bridges, in order to keep them in service until they require necessary retrofit or rebuild in appropriate time.

Many recent damages of old steel bridge structures due to corrosion had drawn attention to the importance of older bridge's condition, leading to intensified inspection protocols and numerous eventual retrofits or replacements [1-3]. It has been proved that the corrosion played a significant role in the catastrophic collapse of both the Silver Bridge (Point Pleasant, WV) in 1967 and the Mianus River Bridge (Connecticut) in 1983, USA [1]. Further, there are more than 50,000 steel railway bridges in Japan, where more than half of them have been used over 60 years and some bridges are aged over 100 years [4], and it was found that the damage due to corrosion is one of the major factors in repair, reinforcement and replacement of steel bridges.

Detailed and regular inspections are necessary in order to assure the adequate safety and determine maintenance requirements, in bridge infrastructure management. These inspections should form the essential source of information to carry out a comprehensive evaluation of its current capacity. Here, ultimate or tensile strength can be defined as the maximum stress that a material can withstand while being stretched or pulled before necking, and the maximum load-carrying capacity is the maximum force that a structural member can sustain. The number of steel bridge 
infrastructures in the world is steadily increasing as a result of building new steel structures and extending the life of older structures. Most of these structures are subjected to corrosion due to environmental exposure which can reduce their carrying capacities. So, there is a need of more brisk and accurate assessment method which can be used to make reliable decisions affecting the cost and safety.

Further, it is known that the corrosion wastage and the stress concentration caused by the surface irregularity of the corroded steel plates influence the remaining strength of the corroded steel plates [5]. Therefore, study the effect of different forms of corrosion to the remaining strength capacities of the existing structure is a vital task for the maintenance management of steel highway and railway infrastructures.

\section{Overview and Scope of the Study}

Usually, the accurate predictions are based on how accurately statistical parameters are estimated and therefore mainly depends on experimental and field data. In the past few decades, several experimental studies and detailed investigations of corroded surfaces were done by some researchers in order to introduce methods of estimating the remaining strength capacities of corroded steel plates [6-8]. But, to develop a more reliable strength estimation technique, only experimental approach is not enough as actual corroded surfaces are different from each other. Further, due to economic constraints, it is not possible to conduct tests for each and every aged bridge structure within their bridge budgets. Therefore, bridge engineers are faced with the lack of experimental and field data. Therefore, nowadays, the use of numerical analysis method could be considered to have a reliable estimation in bridge maintenance industry [9].

Sidharth [10] stated the importance and reviewed the abreast development in the FE analysis technique used to study the corrosion effect on the plates. Ahmmad and Sumi [11] investigated the deformability of corroded steel plates under quasistatic uniaxial tension through both experimental and numerical analyses. They proposed empirical formulae to estimate the reduction in deformability and energy absorption capacity due to pitting corrosion and general corrosion under uniaxial tension. Paik et al. [12, 13] studied the ultimate strength of pitted plates under axial compression and in-plane shear. They also derived empirical formulae for predicting the ultimate compressive strength and shear strength of pitted plates. Ok et al. [14] carried out the nonlinear finite element analyses of panels with various locations and sizes of pitting corrosion, and multivariable regression method is applied to derive new formulae to predict ultimate strength of unstiffened plates with localized corrosion. Therefore, it can be seen that the finite element analysis method has now become the most common, powerful, and flexible tool in rational structural analysis and makes it possible to predict the strength of complex structures more accurately than existing classical theoretical methods. So, one objective of this paper is to present the analytical results of many actual corroded steel members and compare them with their experimental results in order to establish an analytical methodology to estimate the remaining yield and tensile strengths.

Further, it is not easy to measure several thousands of points, to accurately reproduce the corroded surface by numerical methods, and to predict the behavior of that corroded member more precisely. Therefore, study the effect of corroded surface data measurement intensity on their present load-carrying capacities, and investigation of the possibility of establishing a simple and accurate procedure to predict the remaining strength capacities of a corroded steel member by measuring lesser number of points with an acceptable accuracy level would be a vital task for the maintenance management of steel highway and railway infrastructures. So, the second objective of this paper is to investigate the effect of the measuring points and establish a methodology to estimate the remaining strength of corroded steel members through a numerical approach.

\section{Preliminary Investigation and Classification of Corroded Specimens}

In this study, 42 specimens (21 each from flange and web, denoted as FT and WT, resp.) cut out from a steel bridge girder of Ananai River in Kochi Prefecture on the shoreline of the Pacific Ocean, which had been used for about hundred years. Before conducting the thickness measurements, the rust and paint on the surface were removed by using a steel wire brush and then applying high-pressure water in order to preserve its original corrosion surface irregularities. Then the thicknesses of all scratched specimens were measured by using a laser displacement gauge, and the statistical thickness parameters such as average thickness $\left(t_{\mathrm{avg}}\right)$, minimum thickness $\left(t_{\min }\right)$, standard deviation $\left(\sigma_{\mathrm{st}}\right)$, and coefficient of variability $(\mathrm{CV})$ were calculated from the measurement results. First, the tensile testing was performed for the four corrosion-free specimens (each two from flange and web) cut down smoothly from both sides of corroded steel plate. The fundamental mechanical properties of the material (which are not involved in the geometry of the specimen), such as elastic modulus, Poisson's ratio, yield stress, tensile strength, and the elongation, were obtained as shown in Table 1. It is noted that these specimens have the equality with the SS400 Japanese Industrial Standards. And also the web and flange have almost the same properties. Then the tensile tests were performed by using a hydraulic loading test machine (maximum load: $120 \mathrm{kN}$ ) and the loading velocities of $0.2 \mathrm{~mm} / \mathrm{min}$ at elastic region and $0.5 \mathrm{~mm} / \mathrm{min}$ at plastic region for all 42 corroded specimens in order to clarify their remaining strength capacities. The JIS No.5 test specimen is shown in Figure 1.

It is necessary to categorize the different corrosion conditions which can be seen in actual steel structures, into few general types for better understanding of their remaining strength capacities considering their visual distinctiveness, amount of corrosion, and their expected mechanical and ultimate behaviors [15]. Figure 2 shows the relationship between the nominal ultimate stress ratio $\left(\sigma_{b n} / \sigma_{b}\right)$ and the minimum thickness ratio $(\mu)$, where $\sigma_{b n}$ is the nominal 
TABLE 1: Material properties.

\begin{tabular}{lcccccc}
\hline Specimen & $\begin{array}{c}\text { Elastic } \\
\text { modulus/(GPa) }\end{array}$ & Poisson's ratio & $\begin{array}{c}\text { Yield } \\
\text { stress/(MPa) }\end{array}$ & $\begin{array}{c}\text { Tensile } \\
\text { strength/(MPa) }\end{array}$ & $\begin{array}{c}\text { Elongation at } \\
\text { maximum load/(\%) }\end{array}$ & $\begin{array}{c}\text { Elongation after } \\
\text { breaking/(\%) }\end{array}$ \\
\hline $\begin{array}{l}\text { Corrosion-free } \\
\text { plate (flange) }\end{array}$ & 198.9 & 0.272 & 308.7 & 418.7 & 19.28 & 40.12 \\
$\begin{array}{l}\text { Corrosion-free } \\
\text { plate (web) }\end{array}$ & 192.7 & 0.284 & 291.1 & 415.4 & 20.82 & 39.65 \\
SS400 JIS & 200.0 & 0.300 & $245 \sim$ & $400 \sim 510$ & 21.00 & - \\
\hline
\end{tabular}

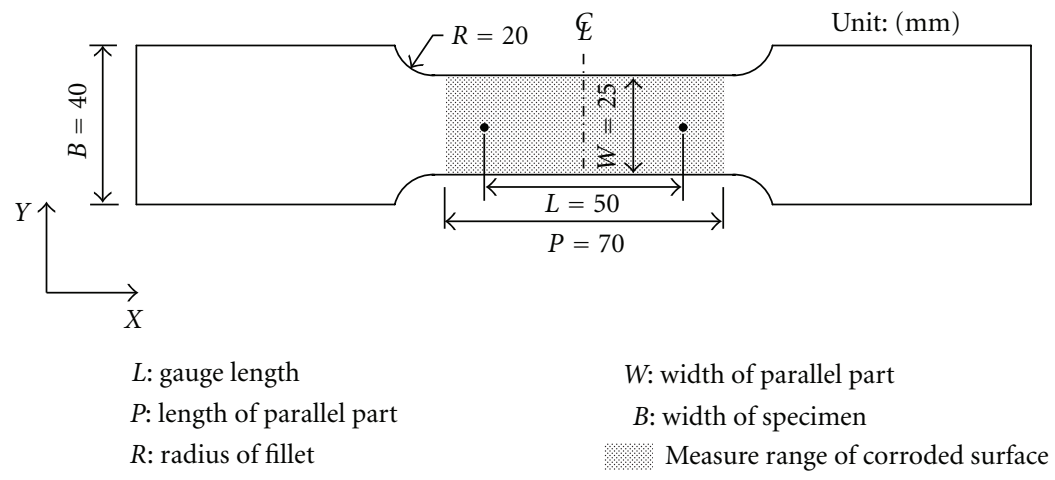

Figure 1: JIS no. 5 specimen for tensile test.

ultimate stress (which is the stress calculated on the basis of the net cross-section of a specimen without taking into account the effect of geometric discontinuities) and $\sigma_{b}$ is the ultimate stress of corrosion-free plate. Here, the minimum thickness ratio $(\mu)$ is defined as:

$$
\mu=\frac{t_{\min }}{t_{0}}
$$

Therefore, three different types of corrosion levels were identified according to their severity of corrosion, and they are classified accordingly as follows:

$$
\begin{gathered}
\mu>0.75, \text { minor corrosion } \\
0.75 \geq \mu \geq 0.5, \text { moderate corrosion } \\
\mu<0.5, \text { severe corrosion }
\end{gathered}
$$

There, the initial thickness $\left(t_{0}\right)$ of flange specimens and web specimens is $10.5 \mathrm{~mm}$, and $10.0 \mathrm{~mm}$ respectively. The significance of three proposed corrosion conditions can be identified even with the visual examination of those members, as members with minor corrosion have tiny corrosion pits (less than $3 \mathrm{~mm}$ depth) throughout the member, members with moderate corrosion have few considerable corroded pits (depth of 3-5 mm) in some places while many noncorroded portions also remain widely, and members with severe corrosion have several extensive corroded regions (maximum corrosion depth over $5 \mathrm{~mm}$ ). Three specimens, FT-22, FT18 , and FT-15 with minor, moderate, and severe corrosion conditions, respectively, are shown in Figure 3.

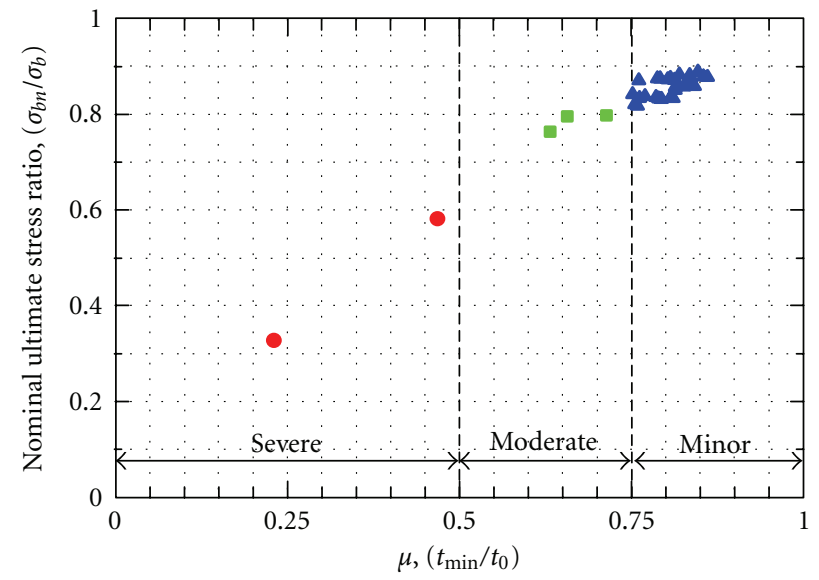

- Level I (minor corrosion)

- Level II (moderate corrosion)

- Level III (severe corrosion)

FIGURE 2: Relationship of ultimate stress ratio and minimum thickness ratio $(\mu)$.

\section{Numerical Analysis}

4.1. Analytical Model. The nonlinear finite element analyses were performed for the specimens with different corrosion conditions in order to clarify the yield and tensile strengths, failure surfaces, and the ultimate behaviors of corroded members. The 3D isoparametric hexahedral solid element with eight nodal points (HX8M) and updated Lagrangian method based on incremental theory were adopted in those analyses. Nonlinear elastic-plastic material, 


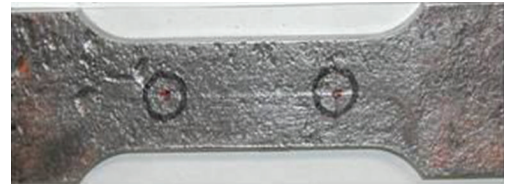

(a)

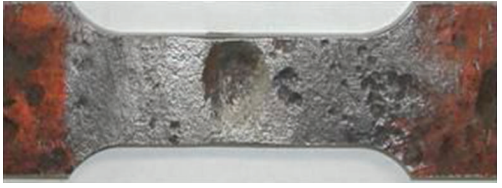

(b)

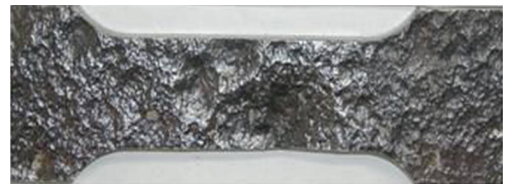

(c)

Figure 3: Plates with (a) minor corrosion [FT-22], (b) moderate corrosion [FT-18], and (c) severe corrosion [FT-15].

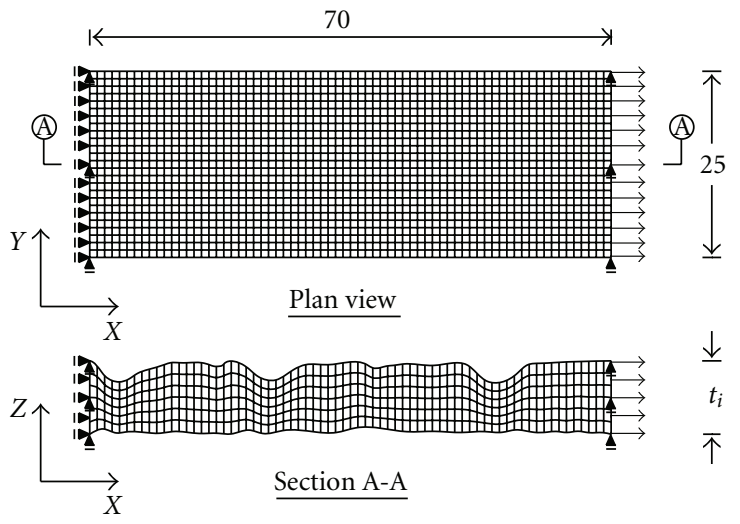

FIgURE 4: Analytical model of corroded member.

Newton-Raphson flow rule, and Von Mises yield criterion were assumed for material properties. Further, an automatic incremental-iterative solution procedure was performed until they reached to the predefined termination limit.

The analytical models with length and width dimensions of $70 \mathrm{~mm} \times 25 \mathrm{~mm}$ ( $X$ and $Y$ directions) were modeled with their respective corrosion conditions. One edge of the member's translation in $X, Y$, and $Z$ directions was fixed, and only the $Y$ and $Z$ direction translations of the other edge (loading edge) were fixed to simulate with the actual experimental condition. Then the uniform incremental displacements were applied to the loading edge as shown in Figure 4.

4.2. Ductile Fracture Criterion. The "Stress Modified Critical Strain Model (SMCS)" was proposed by Kavinde and Deierlein, to evaluate the initiation of ductile fracture as a function of multiaxial plastic strains and stresses [16]. This method was adopted in this analytical study. In SMCS criterion, the critical plastic strain $\left(\varepsilon_{P}^{\text {Critical }}\right)$ is determined by the following expression:

$$
\varepsilon_{P}^{\text {Critical }}=\alpha \cdot \operatorname{Exp}\left(-1.5 \frac{\sigma_{m}}{\sigma_{e}}\right)
$$

where $\alpha$ is the toughness index and the stress triaxiality $T=$ $\left(\sigma_{m} / \sigma_{e}\right)$, a ratio of the mean or hydrostatic stress $\left(\sigma_{m}\right)$, and the effective or von Mises stress $\left(\sigma_{e}\right)$. The toughness index $\alpha$ is a fundamental material property and hence obtained from the tensile test conducted for the noncorroded specimen. The ultimate strength of each corroded specimen was calculated accordingly by using the SMCS criterion and compared with their experimental ultimate capacities to understand the feasibility of the numerical modeling approach for remaining strength estimation of corroded steel plates with different corrosion conditions.

4.3. Analytical Results. The yield and ultimate strengths in analytical prediction were estimated and compared with that of the experimentally obtained values to evaluate the accuracy of the used analytical model. The percentage error in yield and tensile strengths in analytical predictions are calculated as

\%Error in $P_{y}$

$$
=\left|\frac{P_{y}[\text { Analytical }]-P_{y}[\text { Experimental }]}{P_{y}[\text { Experimental }]}\right| \cdot 100
$$

\%Error in $P_{b}$

$$
=\left|\frac{P_{b}[\text { Analytical }]-P_{b}[\text { Experimental }]}{P_{b}[\text { Experimental }]}\right| \bullet 100 .
$$

At first, FEM modeling of the noncorroded specimen was done with the above-described modeling and analytical features to understand the accuracy of the adopted procedure. It was found that the analytical model results were almost the same as the experimental results with having a negligible percentage error of $0.03 \%$ and $0.02 \%$ in yield and tensile strengths, respectively. Then, all other experimentally successful specimens were modeled accordingly, and their yield and ultimate strengths were compared with the experimentally obtained values.

Figure 5 shows the comparison of experimental and analytical load-elongation curves and stress distribution at ultimate load of the specimen FT-22, having minor corrosion. Figure 5(a) shows a very good agreement of the load-elongation behavior, and the percentage errors in yield and tensile strength predictions of the analytical models are $2.11 \%$ and $0.56 \%$, respectively. Further, a similar failure surface was obtained as shown in Figure 5(b).

Then, the members with moderate corrosion were also analyzed and compared with their respective experimental results. Figure 6(a) shows the comparison of the loadelongation behavior of moderately corroded member, FT-18, and it shows that a very good comparison in experimental and analytical results can be obtained. There, the percentage errors in yield and tensile strength predictions are $0.84 \%$ and $0.49 \%$, respectively. Further, Figure 6 (b) shows ultimate stress distribution of specimen FT-18 and it is, revealed that 


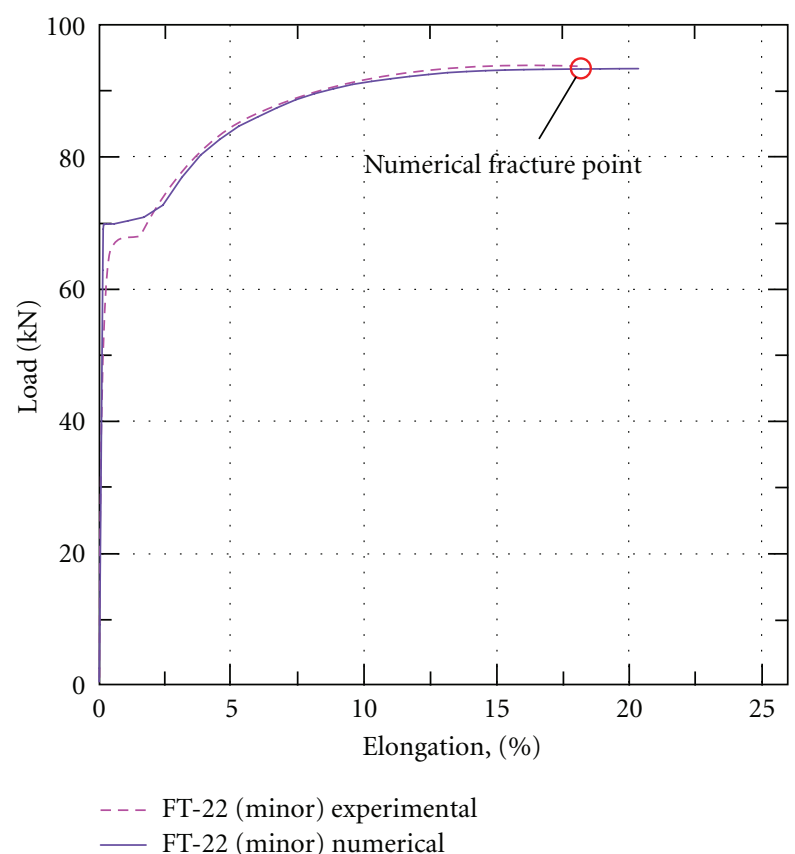

(a)

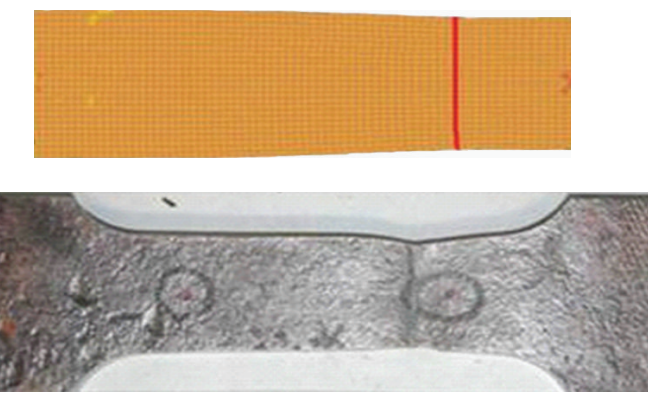

Stress

(MPa)

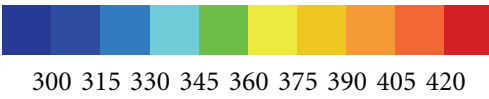

(b)

FIgURE 5: (a) Comparison of experimental and analytical load-elongation curves and (b) stress distribution at ultimate load for the minor corrosion member [FT-22].

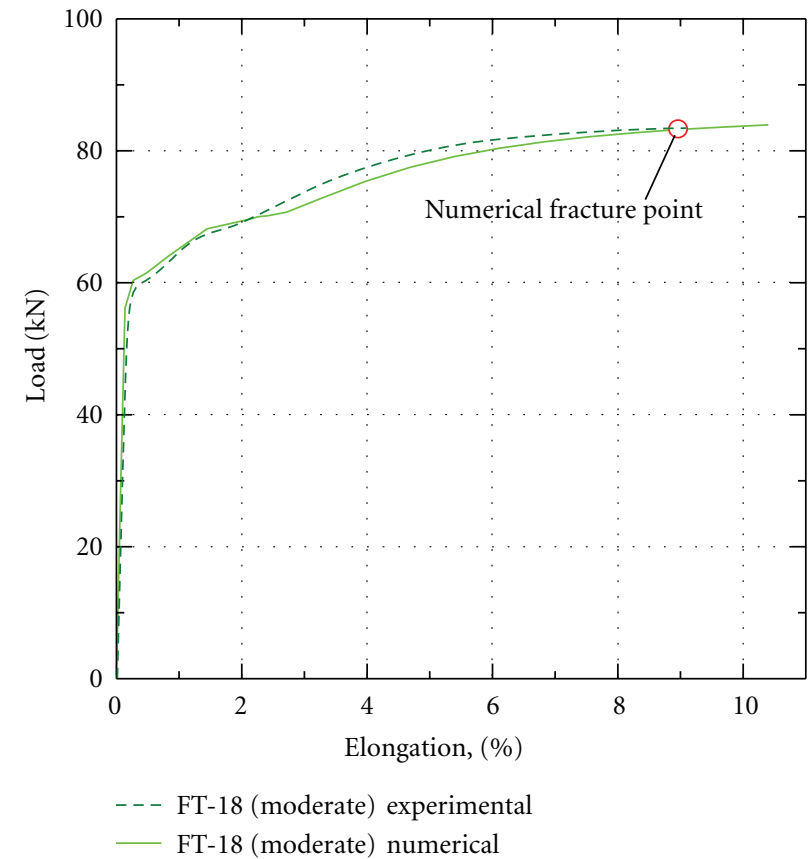

(a)
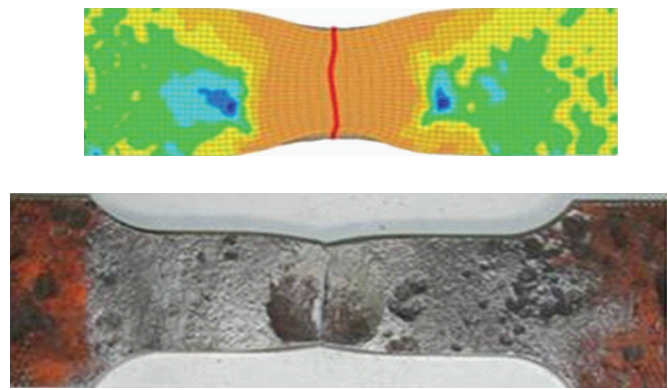

Stress

(MPa)

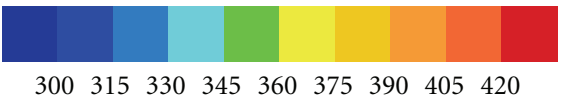

(b)

Figure 6: (a) Comparison of experimental and analytical load-elongation curves and (b) stress distribution at ultimate load for the moderate corrosion member [FT-18].

both the experimental and analytical failure surfaces are in good agreement as well.

Finally, the severely corroded members also analyzed and observed their yield and ultimate behavior and their failure surfaces. Figure 7(a) shows the comparison of experimental and analytical load-elongation behavior of severely corroded specimen FT-15. The percentage errors in yield and tensile strength predictions of member FT-15 shown in Figure 7(a) 


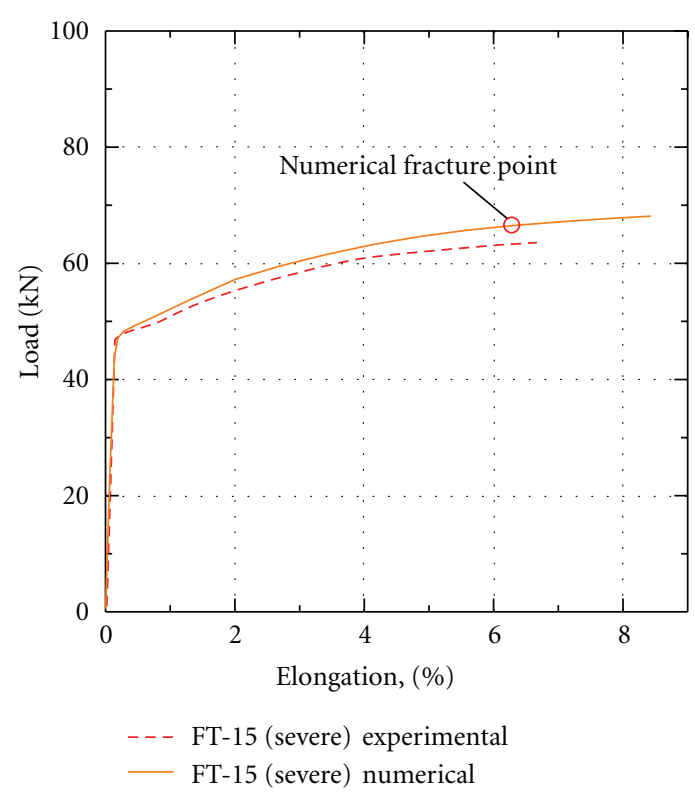

(a)
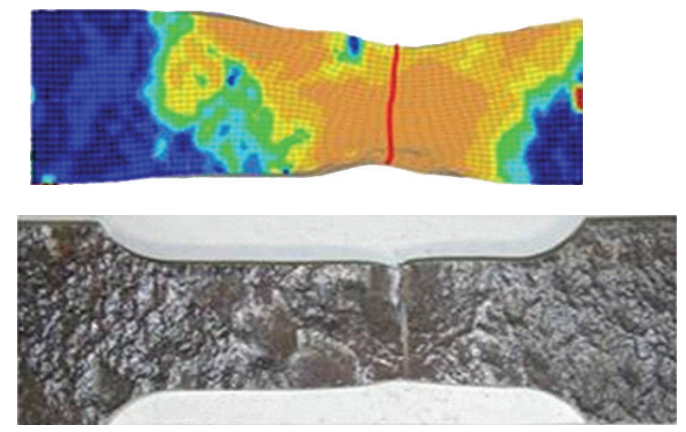

Stress

$(\mathrm{MPa})$

(b)

Figure 7: (a) Comparison of experimental and analytical load-elongation curves and (b) stress distribution at ultimate load for the severe corrosion member [FT-15].

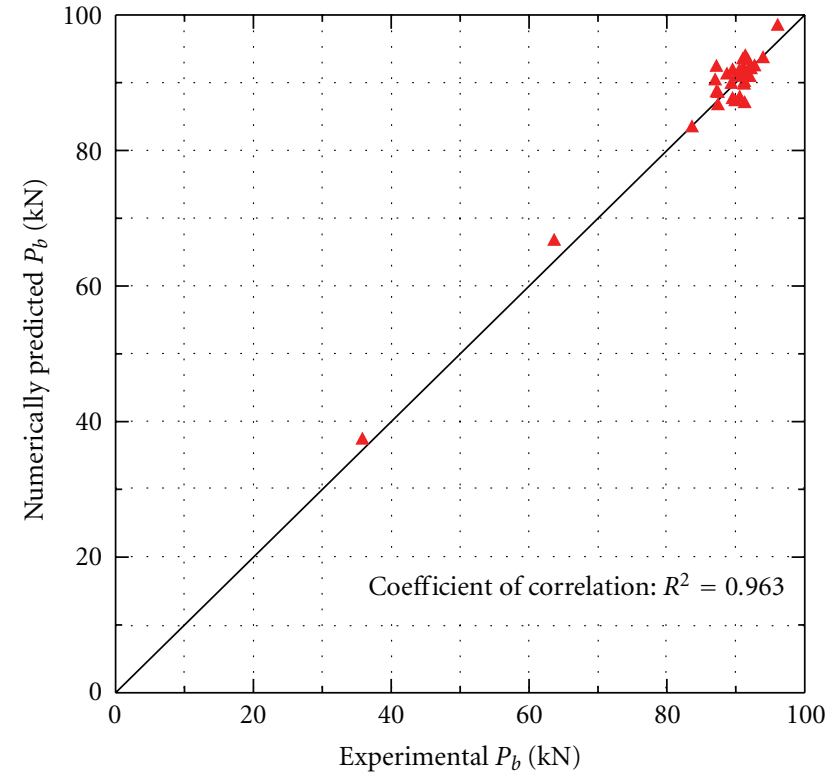

Figure 8: Comparison of experimental and analytical ultimate load capacities.

are $0.19 \%$ and $4.48 \%$, respectively. Here, even though the ultimate behavior of severe corroded specimen shows a slight difference, Figure 7(b) shows that a similar failure surface can be obtained from the analytical results as in the experimental analysis.
4.4. Discussion. Figure 8 shows the comparison of ultimate load capacities of experimental and numerical analyses conducted for all the experimentally successful flange and web specimens. Having a coefficient of correlation of $R^{2}=$ 0.963 indicates the accuracy and the possibility of numerical investigation method to predict the tensile strength of actual corroded specimens.

Even though the results of numerical predictions for yield and ultimate strengths of minor and moderate corroded members show a very good comparison with the experimental results, severe corrosion members show a little bit deviation in their ultimate strength predictions. The reason could be that some microscopic cracks could also have been builtup with the development of corrosion, which could eventually results in a loss of strength. Therefore, we can see a loss of tensile strength in experimental analyses more than expected or predicted by analytical models in severely corroded specimens. So, careful microscopic observations for severe corroded surfaces, and smoothing them neatly could reduce such errors with analytical prediction.

\section{Effect of Measuring Points}

Even though it is an exigent task to conduct detailed investigations of all existing steel structures as the number of steel structures is steadily increasing in the world, it is necessary to assess those structures in a regular basis to ensure their safety and determine the necessary maintenance. Therefore, developing a rapid and accurate methodology to estimate the remaining strength capacities of steel infrastructures is a vital task in maintenance engineering. 


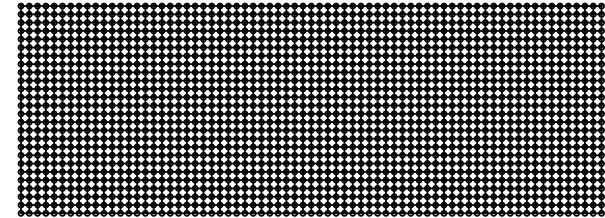

$\underline{\text { Model } 1(1 \mathrm{~mm})}$

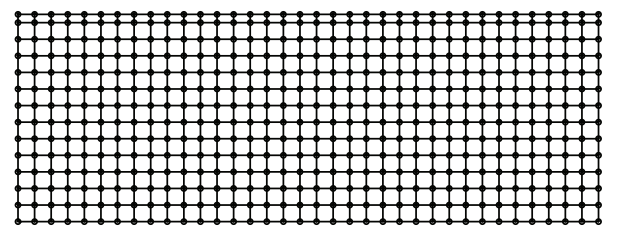

Model $2(2 \mathrm{~mm})$

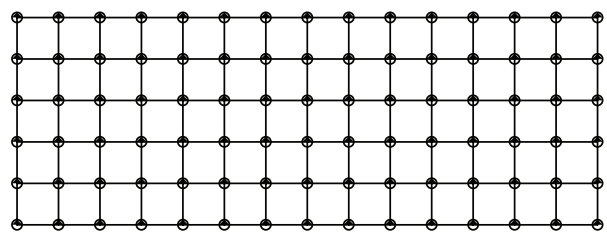

Model 3 (5 mm)

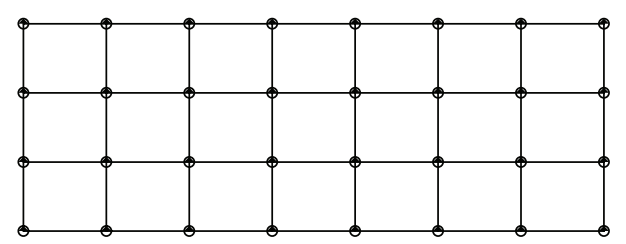

Model 4 (10 mm)

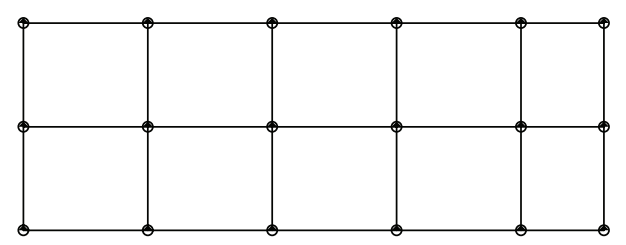

Model $5(15 \mathrm{~mm})$

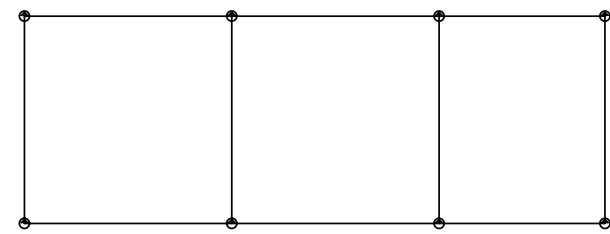

Model 6 (25 mm)

FIGURE 9: RCSM analytical models.
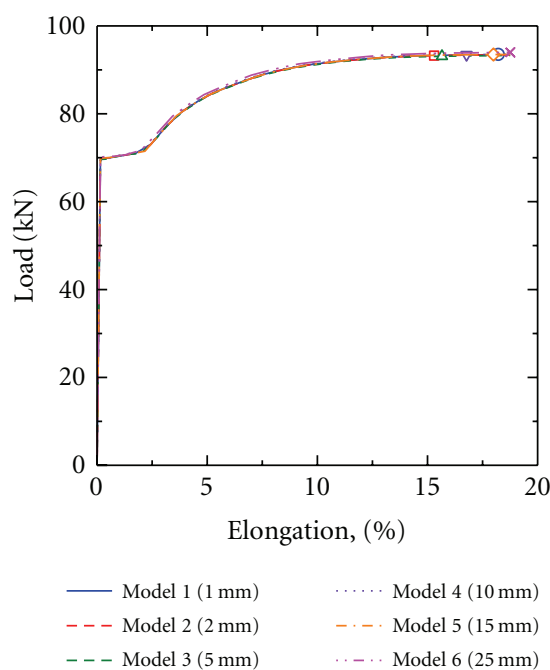

(a)

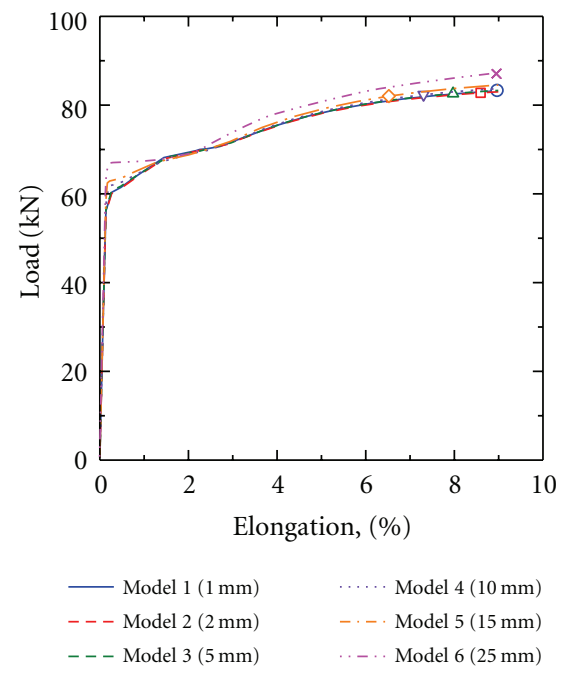

(b)

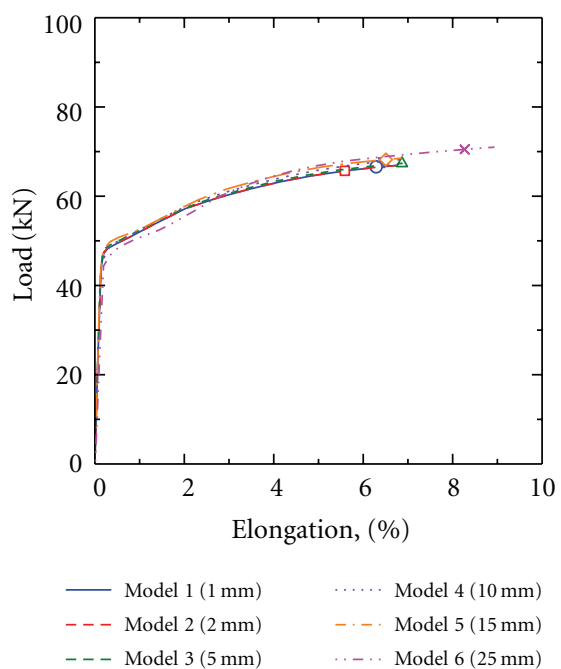

(c)

FIGURE 10: Comparison of load-elongation curves of RCSM models: (a) minor corrosion member FT-22, (b) moderate corrosion member FT-18, and (c) severe corrosion member FT-15.

\subsection{Numerical Modeling with Regular Corroded Surface Measurements (RCSMs) Methods}

5.1.1. Analytical Models. The 6 different finite element models, as shown in Figure 9, were modeled and analyzed for each corroded specimen and compared with the results of model 1 with $1 \mathrm{~mm}$ mesh data to understand the effect of corroded surface data intensity with their remaining yield and tensile strength capacities. Total measuring points of the models 1 , $2,3,4,5$, and 6 are $1846,504,90,32,18$, and 8 , respectively.
The same modeling features and analytical procedure as described in section 4 were adopted for all the RCSM model analyses too.

5.1.2. Analytical Results and Discussion. Figure 10 shows the load-elongation behavior of three specimens, FT-22, FT18, and FT-15, with different number of measuring points. It is noticed that the load-elongation behavior is almost the same in all models as shown in Figure 10(a), irrespective of their intensity of corroded surface measurement for 

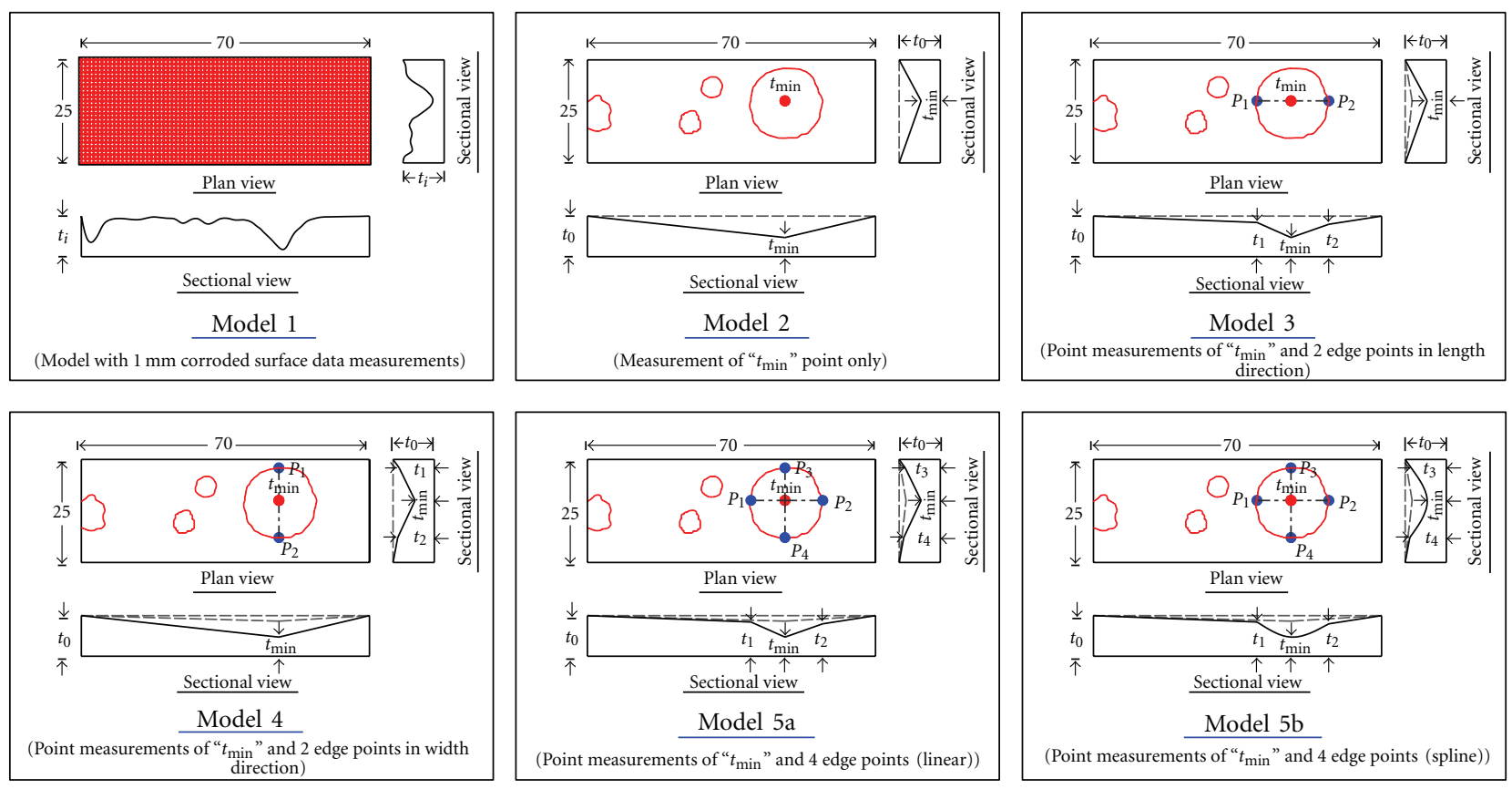

FIgURE 11: SCSM analytical models.

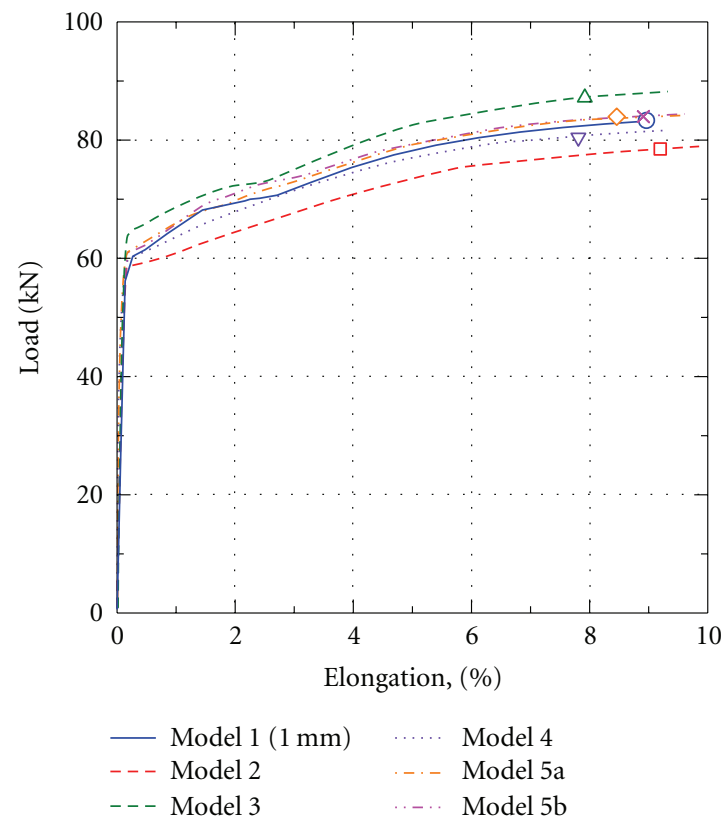

(a)

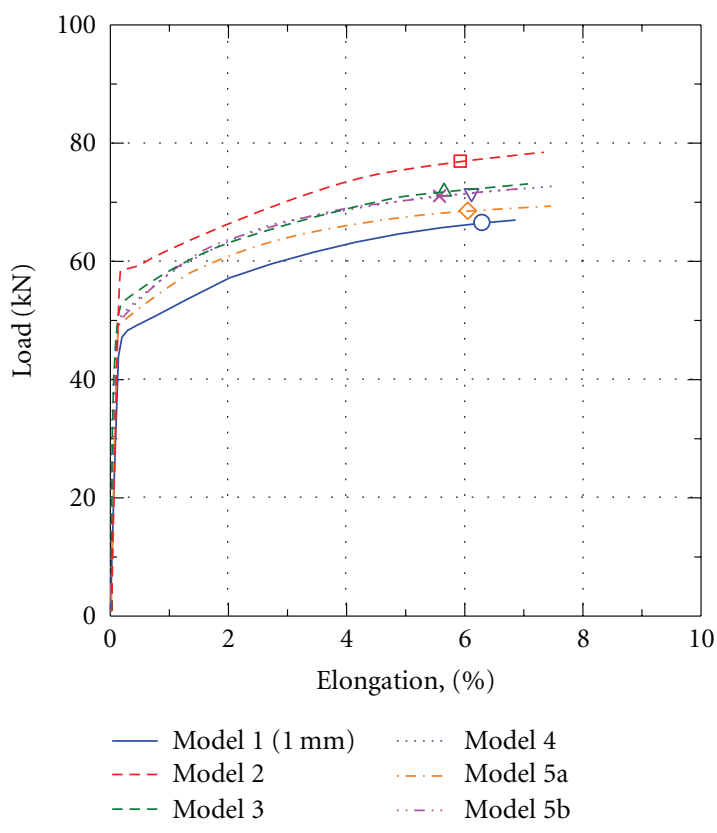

(b)

FIGURE 12: Comparison of load-elongation curves of SCSM models: (a) moderate corrosion member FT-18 and (b) severe corrosion member FT-15.

minor corrosion members. This fact can be comprehended as the overall amount of corrosion or the corrosion attack for a particular location is very small in minor corrosion members. But Figures 10(b) and 10(c) show that the loadelongation behaviors are affected by the coarseness of the measuring points for moderate and severe corrosion members. The yield and tensile strengths along with the respective percentage errors are shown in Table 2. It can be seen that the percentage errors in both yield and tensile strength estimations are increased with the reduction of the intensity of corroded surface measurement points in moderate and severe corrosion members. The reason for this could be the missing of the maximum corroded location or some severe corroded portions during this kind of regular data 
TABLE 2: Yield and tensile strength predictions of different RCSM analytical models.

\begin{tabular}{|c|c|c|c|c|c|c|}
\hline \multirow{2}{*}{ Model no. } & \multicolumn{3}{|c|}{ Yield load, $P_{y} /(\mathrm{kN})$} & \multicolumn{3}{|c|}{ Tensile load, $P_{b} /(\mathrm{kN})$} \\
\hline & FT-22 & FT-18 & FT-15 & FT-22 & FT-18 & FT-15 \\
\hline 1 & $69.18(-)$ & $60.35(-)$ & $47.18(-)$ & $93.43(-)$ & $83.23(-)$ & $66.49(-)$ \\
\hline 2 & $69.25(0.10 \%)$ & $60.09(0.43 \%)$ & $47.48(0.63 \%)$ & $93.24(0.20 \%)$ & $82.77(0.55 \%)$ & $65.69(1.20 \%)$ \\
\hline 3 & $68.88(0.43 \%)$ & $60.71(0.60 \%)$ & $46.63(1.16 \%)$ & $93.09(0.37 \%)$ & $82.60(0.75 \%)$ & $67.36(1.32 \%)$ \\
\hline 4 & $69.27(0.13 \%)$ & $61.73(2.29 \%)$ & $46.36(1.74 \%)$ & $93.44(0.00 \%)$ & $82.34(1.06 \%)$ & $67.85(2.06 \%)$ \\
\hline 5 & $69.18(0.00 \%)$ & $62.47(3.51 \%)$ & $48.34(2.44 \%)$ & $93.48(0.05 \%)$ & $82.02(1.45 \%)$ & $68.22(2.61 \%)$ \\
\hline 6 & $70.01(1.20 \%)$ & $62.78(4.03 \%)$ & $44.92(4.79 \%)$ & $93.98(0.58 \%)$ & $87.18(4.74 \%)$ & $70.52(6.08 \%)$ \\
\hline
\end{tabular}

(一)\% Error in strength estimation.

TABLE 3: Yield and tensile strength predictions of different SCSM analytical models.

\begin{tabular}{lcccc}
\hline Model no. & \multicolumn{2}{c}{ Yield load, $P_{y} /(\mathrm{kN})$} & \multicolumn{2}{c}{ Tensile load, $P_{b} /(\mathrm{kN})$} \\
\hline 1 & $60.35(-)$ & FT-15 & FT-18 & $66.49(-)$ \\
2 & $55.84(7.47 \%)$ & $55.91(18.50 \%)$ & $78.50(5.68 \%)$ & $76.96(15.74 \%)$ \\
3 & $64.35(6.62 \%)$ & $51.39(8.92 \%)$ & $87.19(4.76 \%)$ & $71.79(7.97 \%)$ \\
4 & $56.78(5.92 \%)$ & $50.31(6.64 \%)$ & $80.42(3.37 \%)$ & $71.55(7.61 \%)$ \\
$5 \mathrm{a}$ & $60.88(0.89 \%)$ & $48.81(3.46 \%)$ & $83.95(0.86 \%)$ & $68.56(3.12 \%)$ \\
$5 \mathrm{~b}$ & $60.93(0.96 \%)$ & $49.18(4.24 \%)$ & $83.98(0.91 \%)$ & $71.06(6.87 \%)$ \\
\hline
\end{tabular}

$(-) \%$ Error in strength estimation.

measurement. Therefore, the effect of stress concentration would diminish in some of the models considered in this RCSM method, which have lesser number of measuring points. So the remaining strengths are overestimated with the increase of coarseness of the data measurement, which could lead the infrastructure in danger on decisions taken regarding its maintenance management plan. So, a special surface measurement method with lesser number of measuring points, concerning the severity of corrosion and stress concentration, is required for moderate and severe corrosion members.

\subsection{Numerical Modeling with Special Corroded Surface Measurements (SCSMs) Methods}

5.2.1. Analytical Models. Five different models were created by considering the irregularity of the corroded surface and stress concentration effect, and their analytical results were compared with the model with $1 \mathrm{~mm}$ corroded surface data (model 1). Figure 11 shows different SCSM analytical models used in this study. The outer edges were taken as the initial thickness $\left(t_{0}\right)$ in all models except model 1. model 2 was developed by using the measurement of minimum thickness point $\left(t_{\min }\right)$ only. There, the surface irregularity was modeled by using a linear variation between $t_{\min }$ point and the edges of the corroded plate. Model 3 and model 4 were created with $t_{\min }$ point and two other thickness measurements taken at the edges of the corroded pit in longitudinal direction and width direction, respectively. These models also were created by considering the linear variation among measured points and plate boundaries. Models 5a and $5 \mathrm{~b}$ consist of five thickness measurements of the corroded pit including its $t_{\min }$ and two points each in longitudinal and width directions. Then, linear and spline variations were used to model the corroded portion in model $5 \mathrm{a}$ and model $5 \mathrm{~b}$, respectively. Further, the surface irregularity was modeled by using a linear variation between the corroded pit and plate edges in both models.

Same modeling features, nonlinear elastic-plastic material properties, and analytical procedure were adopted for all the above models, and the analyses were performed untill they reach to their predefined termination limits. Then, their load-elongation behaviours, yield and tensile strengths and ultimate behaviors were compared with model 1 with $1 \mathrm{~mm}$ corroded surface data, to understand the effect of SCSM models having lesser number of measuring points.

5.2.2. Analytical Results and Discussion. The load-elongation behavior of the different SCSM models of the moderate corroded specimen FT-18 and the severe corroded specimen FT-15 is shown in Figures 12(a) and 12(b) respectively. Here, significant differences on load-elongation behaviors can be seen in models 2,3 , and 4 compared to model 1 which is developed with more detailed data measurements of the corroded surface. These differences appeared because models 2,3 , and 4 could not be able to accurately model the corroded pit and the surface irregularity of the real corroded specimen. On the other hand, it can be seen that the differences on loadelongation behaviors are comparatively smaller in models $5 \mathrm{a}$ and $5 b$, as they could model the corroded pit more accurately than other models. Since these models (models $5 \mathrm{a}$ and $5 \mathrm{~b}$ ) require only five thickness measurements of the moderately or severely corroded portion, they can be considered as a very useful analytical method in brisk assessment of residual strength capacities of corroded steel plates. 
The yield and tensile strengths along with their respective percentage errors are shown in Table 3. There, it is revealed that models $5 \mathrm{a}$ and $5 \mathrm{~b}$ show smaller percentage error in yield and tensile strength predictions than the other models and model 5a gave the closest remaining strength capacity estimations to model 1 results. Further, it was noted that, even though the moderate corrosion specimen (FT-18) shows a negligible percentage error in estimating their yield and tensile strengths, severe corroded specimen (FT-15) has a bit larger value of it. The reason for this could be the missing of some other severely corroded portions, as severe corroded specimens have several extensive corroded pits on their corroded surfaces. Therefore, further development of SCSM models is deemed necessary in order to represent the corroded surface irregularity more accurately for severe corroded members in future studies.

\section{Conclusions}

The surface irregularity measurement, tensile testing, and nonlinear FEM analyses were conducted for corroded steel specimens obtained from the scrapped plate girder which had been used for about 100 years with severe corrosion. Main conclusions obtained from this study are as follows.

(1) The corrosion causes strength reduction of steel plates, and minimum thickness ratio $(\mu)$ can be used as a measure of the level of corrosion and their strength degradation.

(2) Nonlinear FEM analytical results indicated a very good comparison of the experimental and the analytical load-elongation behaviors for all three classified corrosion types. Further, failure surfaces of those specimens too showed a very good comparison with the experimental results. Therefore, the adopted numerical modeling technique can be used to predict the remaining strength capacities of actual corroded members more accurately.

(3) Though the intensity of corroded surface measurement is not very significant for minor corrosion members, it was revealed that it affects the moderate and severe corrosion members considerably in prediction of their remaining strength capacities.

(4) Therefore, a regular coarse surface data measurement is sufficient for minor corroded members. But a special surface measurement method with $t_{\min }$ point and few thickness measurements of the corroded pit concerning the severity of corrosion and stress concentration is necessary for moderate and severe corrosion members to estimate their remaining strength capacities.

\section{References}

[1] NSBA, "Corrosion protection of steel bridges," in Steel Bridge Design Handbook, chapter 23, National Steel Bridge Alliance, 2006.

[2] T. Kitada, "Considerations on recent trends in, and future prospects of, steel bridge construction in Japan," Journal of
Constructional Steel Research, vol. 62, no. 11, pp. 1192-1198, 2006.

[3] T. Natori, K. Nishikawa, J. Murakoshi, and T. Ohno, "Study on characteristics of corrosion damages in steel bridge members," Journal of Structural Mechanics and Earthquake Engineering, vol. 668, no. 54, pp. 299-311, 2001 (Japanese).

[4] I. Sugimoto, Y. Kobayashi, and A. Ichikawa, "Durability evaluation based on buckling characteristics of corroded steel deck girders," Quarterly Report of RTRI, vol. 47, no. 3, pp. 150155, 2006.

[5] A. Kariya, K. Tagaya, T. Kaita, and K. Fujii, "Mechanical properties of corroded steel plate under tensile force," in Proceedings of the 3rd International Structural Engineering and Construction Conference (ISEC '03), pp. 105-110, Shunan, Japan, 2003.

[6] M. Matsumoto, Y. Shirai, I. Nakamura, and N. Shiraishi, "A proposal of effective thickness estimation method of corroded steel member," Bridge Foundation Engineering, vol. 23, no. 12, pp. 19-25, 1989 (Japanese).

[7] A. Muranaka, O. Minata, and K. Fujii, "Estimation of residual strength and surface irregularity of the corroded steel plates," Journal of Structural Engineering, vol. 44A, pp. 1063-1071, 1998 (Japanese).

[8] A. Kariya, K. Tagaya, T. Kaita, and K. Fujii, "Basic study on effective thickness of corroded steel plate and material property," in Proceedings of the Annual Conference of JSCE, pp. 967-968, 2003.

[9] T. Kaita, Y. Kawasaki, H. Isami, M. Ohga, and K. Fujii, "Analytical study on remaining compressive strength and ultimate behaviors for locally-corroded flanges," in Proceedings of the East Asian Stock Exchange Conference (EASEC '08), Taipei, Taiwan, 2008.

[10] A. A. P. Sidharth, "Effect of pitting corrosion on ultimate strength and buckling strength of plates-a review," Digest Journal of Nanomaterials and Biostructures, vol. 4, no. 4, pp. 783-788, 2009.

[11] M. M. Ahmmad and Y. Sumi, "Strength and deformability of corroded steel plates under quasi-static tensile load," Journal of Marine Science and Technology, vol. 15, no. 1, pp. 1-15, 2010.

[12] J. K. Paik, J. M. Lee, and M. J. Ko, "Ultimate compressive strength of plate elements with pit corrosion wastage," Journal of Engineering for the Maritime Environment, vol. 217, no. 4, pp. 185-200, 2003.

[13] J. K. Paik, J. M. Lee, and M. J. Ko, "Ultimate shear strength of plate elements with pit corrosion wastage," Thin-Walled Structures, vol. 42, no. 8, pp. 1161-1176, 2004.

[14] D. Ok, Y. Pu, and A. Incecik, "Computation of ultimate strength of locally corroded unstiffened plates under uniaxial compression," Marine Structures, vol. 20, no. 1-2, pp. 100-114, 2007.

[15] J. M. R. S. Appuhamy, M. Ohga, T. Kaita, and K. Fujii, "Effect of measuring points on remaining strength estimation of corroded steel plates," in Proceedings of the 9th Pacific Structural Steel Conference (PSSC '10), pp. 1504-1516, Beijing, China, 2010.

[16] A. M. Kanvinde and G. G. Deierlein, "The void growth model and the stress modified critical strain model to predict ductile fracture in structural steels," Journal of Structural Engineering, vol. 132, no. 12, pp. 1907-1918, 2006. 

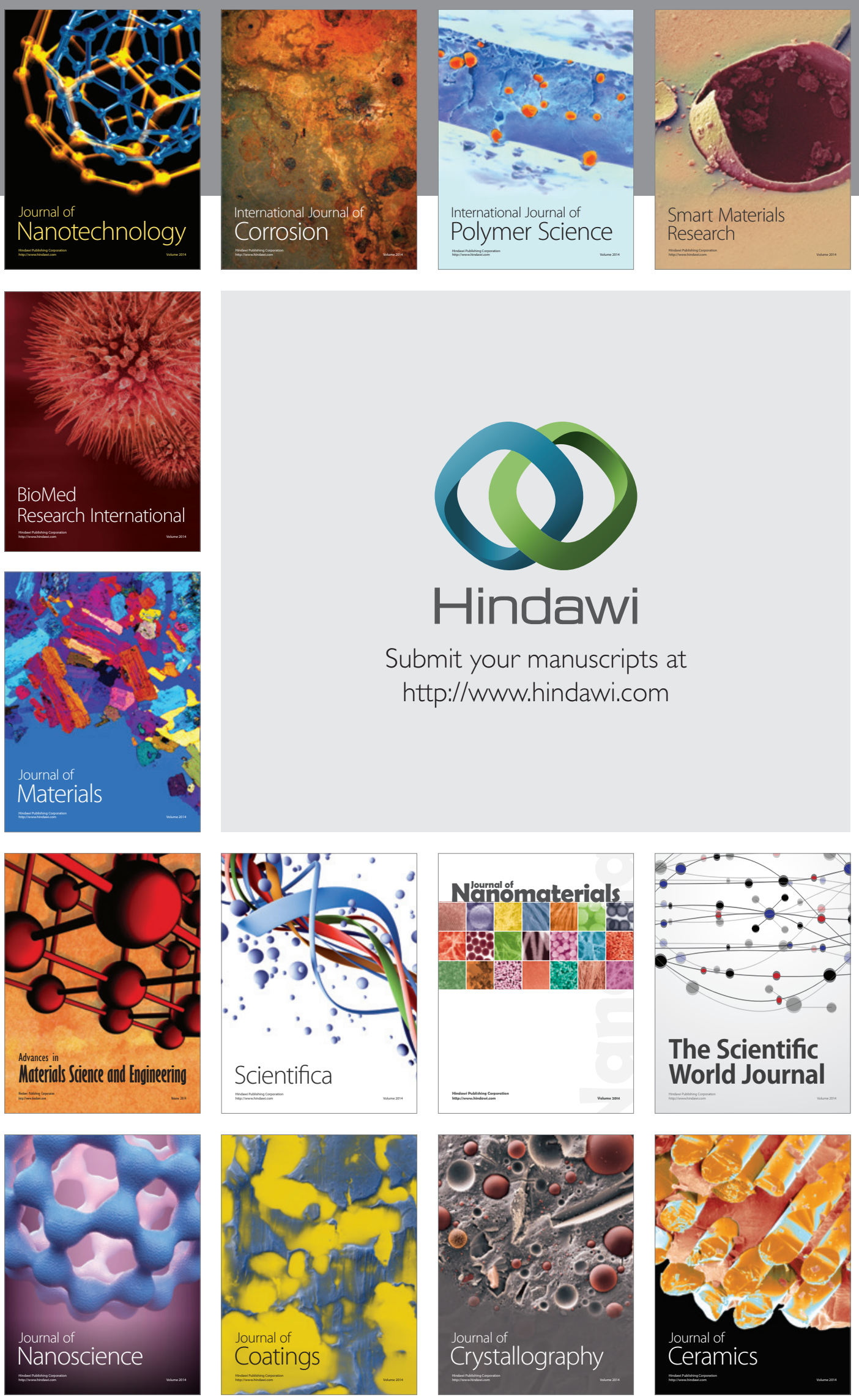

The Scientific World Journal

Submit your manuscripts at

http://www.hindawi.com

\section{World Journal}

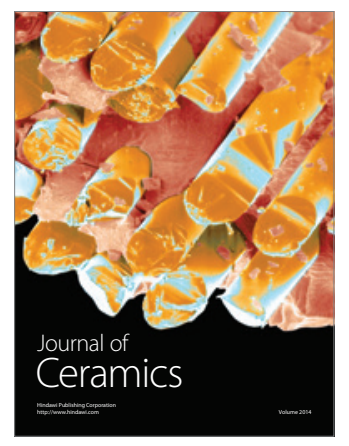

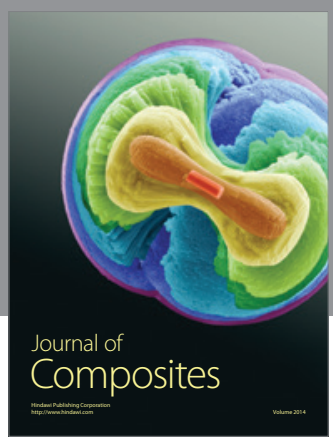
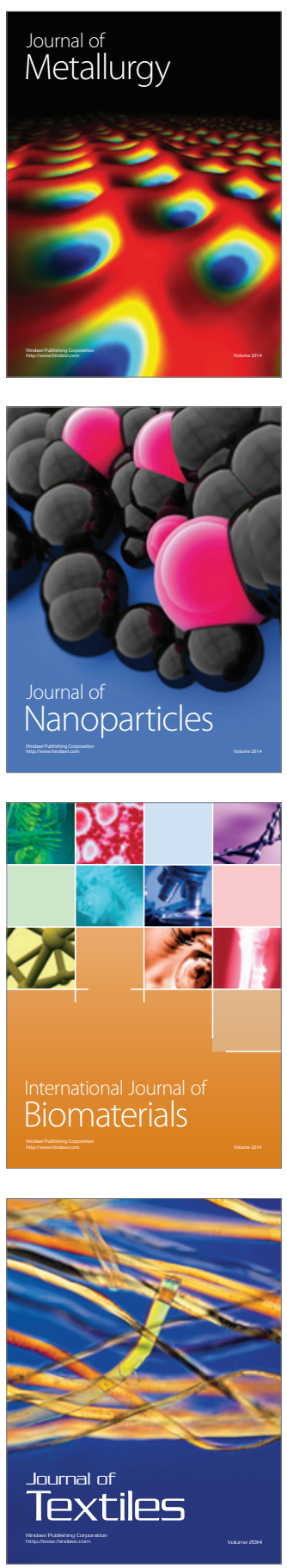